\title{
BENESTAR I POBRESA EN ELS FONAMENTS ECONÒMICS DE L'ISLAM: UNA REFLEXIÓ ECONÒMICA DE L'ALMOINA RELIGIOSA ${ }^{1}$
}

\author{
Josep-Antoni YBARRA \\ Universitat d'Alacant
}

Atenent a la unicitat de les facetes de l'home, l'islam no separa els diversos comportaments de la vida de l'home. És així que els actes econòmics fets per l'home són també induïts per consideracions religioses. Per açò cal afirmar que sota el mantell de l'islam es troben regulats tots els aspectes de la vida de l'home. Aleshores, res té d'estrany que sota el mantell de l'islam capien moltes i diferents situacions que es donen en el món real; unes seran admeses, d'altres, per contra, seran condemnades. Certament que dins de l'amplia diversitat de situacions que es donen en la realitat, l'islam pot ser una guia que pretén conduir de forma correcta el quefer de l'home en la seua vida pública i privada.

Es pot parlar, doncs, de l'islam com una religió de la quotidianitat, que dóna resposta a moltes i molt diverses situacions que de vegades es contradiuen. Això obliga a generalitzar $\mathrm{i}$ de vegades a relativitzar, encara que done l'aparença d'intransigència i de radicalisme interpretatiu.

${ }^{1}$ Aquest treball surt de la reflexió feta en veu alta en les classes d'economia política islàmica en els màsters de relacions euro-àrabs que es feren a les universitats d'Alacant i Girona i al CIDOB de Barcelona al llarg de quasi cinc anys. Molts dels que foren alumnes i avui màsters, són copartícips d'aquestes planes per haver discutit coses que avui es plantegen sistematitzades. 
Atenent a les disparitats de benestar dels estats islàmics o de majoria musulmana, trobem que les diferències són notables. Què diu l'islam sobre el tema?; s'admeten les disparitats en el si de l'islam?; l'islam agreuja o dilueix les diferències? Una reflexió sobre els principis islamics que fonamenten l'economia, permet entendre la justificació del benestar, la riquesa i la pobresa. Aquest és l'objectiu del treball que tractem a través de l'almoina religiosa o zaqãt.

\section{La zaqāt: raó econòmica I social del seu naixement}

La conformació d'un grup social marginal com és l'encapçalat per Mahoma en el seu inici, fa que s'hagueren de prendre mesures de protecció davant d'un ordre social pre-islamic que era dominant en aquell moment i, a més a més, contrari a l'aparició de grups que pogueren ser diferents al de poder establert. Sembla logic, per tant, que una de les primeres propostes que apareix en l'islam per constituir-se com a grup és la de dotar-se d'una organització interna per preservar-se d'elements externs (Etienne, 1987, 64 i ss.; Hasanuz, 1991, 167 i ss.), i a més que fera com un element de dimanització. La zaqăt pot ser el mecanisme que permeta assolir aquesta doble funcio: com a element de cohesió interna i com a element d'expansió externa (Nienhaus, 1990, 123).

Atenent a la primera de les apreciacions fetes, cal assenyalar que la zaqāt apareix com un pagament obligatori de caràcter moral per pertànyer a un grup -l'islam-; la quantia és una altra qüestió. Analitzant la zaqãt com un mecanisme econòmic d'assignació i d'obligatorietat, sobresurt el fet que la pertinença a un grup significa el compliment de les normes del grup, entre les quals hi ha el pagament d'un impost - la zaqāt-, i alhora també el fet de rebre beneficis d'aquesta pertinença a través d'una quantitat de béns i serveis —els fons de la zaqāt. El pagament d'aquest impost estarà relacionat lòicament amb els ingressos que es puguen derivar del fet de pertànyer al grup, i el fet de rebre els beneficis materials directes de la zaqãt - la distribució de les zaqăt- serà determinat per les necessitats dels 
components més desprotegits del grup i que hagen resultat així precisament per la pertinença al grup (Alcorà, $2: 215 ; 9: 60)^{2}$.

La situació més pragmàtica que ens fa conéixer aquesta conformació de grup partint dels mecanismes automàtics d'assignació i d'obligatorietat econòmica des del pagament de la zaqăt, és la de la compensació que reben els orfes, les viudes, els desprotegits, els captius pel fet d'haver contribuït a la consolidació de l'islam per la guerra santa. Es pot pensar que molts d'ells es troben orfes, viudes, desprotegits $i$ captius per haver participat directa $\mathrm{i} / \mathrm{o}$ indirectament en la guerra santa -l'expansió de l'islam. Davant els efectes derivats de l'expansió, s'arriba a establir un pagament que moralment i materialment compense aquells altres que hagen pogut perdre quelcom en el procés d'expansió i de consolidació de l'islam. D'aquesta forma, tan els que han participat directament en el procés d'expansio i han pogut sobreviure a la batalla són compensats amb el bot́ i les terres que han pres als infidels, com també seran compensats tots aquells que hagen pogut participar de forma indirecta (les dones $\mathrm{i}$ les famílies) $\mathrm{i}$ que han perdut els soldats, o aquells guerrers que han estat ferits o mutilats i que seran compensats amb els fons que es poden tenir de la zaqãt.

Si la referència anterior ens ha d'ajudar a entendre la funció de la zaqāt en un fet de protecció concreta, es pot afirmar d'una forma general que, des d'un punt de vista material, la grandaria i la fortalesa del grup és condicionada per la grandària i la fortalesa en el pagament d'aquest impost religiós. En la mesura de la quantitat que es fa del pagament de l'impost - tan pel nombre de persones que ho fa com per la quantitat de riquesa que es concreta en aquest pagament-, serà una mostra de la solidesa del grup i alhora de la capacitat de fer-se més fort i gran. És per açò que es pot entendre la zaqãt com el pagament necessari per a mantenir una estructura sòcio-política i sòcio-econòmica que es troba en l'inici de l'islam. La zaqãt respon així, en un primer cop, al fet que una organització política exigeix un suport financer.

${ }^{2}$ Les citacions alcoràniques corresponen a la traducció de l'Alcorà feta per Julio Cortés i publicada en castellà en 2a edició (1984) a Madrid: Editora Nacional. El primer del dos números que apareixen en cadascuna de les citacions correspon a la süra —capítol de l'Alcorà; el segon número es refereix a l'aleia -versicle d'aquest capítol. 
D'aquesta forma la zaqãt és el pagament obligatori que han de fer els individus - els musulmans- per la mateixa possibilitat de reproducció que garanteix un grup determinat - l'islam. És, doncs, la concretització materialitzada de l'acceptació de les dificultats per sobreviure en el si d'una societat, com és la pre-islàmica, amb pressions i invasions externes continuades, on cal protegir-se en grup, mitjançant el pagament d'una part dels guanys i dels beneficis obtinguts un cop que s'ha arribat a un cert nivell de guany.

El segon aspecte que cal destacar pel que fa als efectes de la zaqät en la seua transcendencia inicial, és la condició d'element d'expansió externa de l'islam. En l'objectiu d'instaurar la zaqāt es troba no solament la presumpció de consolidar el sistema, sinó també d'expandirlo. Aquesta és una idea paral lela a la del repartiment dels guanys obtinguts en la guerra santa. La forma que té l'islam d'expandir-se en els seus orígens, és a través de la consolidació dels drets reials sobre els béns conquerits ${ }^{3}$. Els drets de conquesta es consoliden sempre que hi haja un pagament al grup - l'islam- que es compromet pel seu interés propi a defensar aquesta conquesta. L'islam, doncs, s'erigeix com a defensor de la nova realitat que apareix i també serà proclamat de facto com a sancionador, censor i vigilant de les noves normes que genera (Rodinson, 1993, 216-222). En definitiva, aquesta possibilitat que l'islam adquireix de defensa d'interessos individuals i col·lectius, com també la capacitat de sancionar, permetrà que vaja eixamplant-se una idea general sobre la virtualitat de l'islam, pero, sobretot, que s'instaure una presumpció en el subconscient col-lectiu dels musulmans amb la idea que l'islam protegeix l'expansió. Serà la naixença, la consolidació i l'expansió d'una religió, el que dóna pas a la naixença, la consolidació i l'expansió d'una organització sòcio-política que té raó de ser no en funció de pertànyer a un determinat territori (com podria ser el cas dels estats moderns), sinó pel fet de pertànyer a una religió determinada.

És així que del pagament o de la donació al col-lectiu islamic d'una part de les rendes de les terres, de les propietats i dels beneficis, de la

${ }^{3}$ Açò no és exclusiu de l'islam. Ho podem veure també en la manera en què el cristianisme s'expandeix en l'edat mitjana, o en el procés d'hispanització de Llatinoamèrica. 
mateixa manera que dels béns conquerits, s'aconsegueixen dues coses principalment:

1. A nivell col-lectiu, el compliment de la norma en el pagament de la zaqãt permet que l'islam s'eixample. La zaqãt possibilita que l'islam es fique en una espiral de creixement quant a conquestes i expansió de l'activitat normalitzada dins de les normes islàmiques, pel fet que l'organització que està gestant-se dins d'aquest procés d'expansió i de normalització és la que permetrà obtenir guanys i beneficis a tota la col-lectivitat. S'incentiva, doncs, la conquesta d'aquelles terres que encara no són islàmiques i es confia que, una vegada sotmeses a les normes islamiques, els guanys successius puguen garantir que continue l'espiral de creixement de l'islam.

2. Que aquesta mateixa expansió de l'islam permetrà la seua consolidació. Bàsicament, el pagament de la zaqăt va dirigit en un primer cop a tot un col-lectiu que ha pogut resultar marginat i/o desfavorit dins del procés d'expansio: als desheretats socialment, pobres, malalts, presos, impossibilitats, orfes, convertits a l'islam, deutors per pagar els seus deutes, esclaus per poder alliberar-se, viatgers, etc., i per pagar el salari dels recaptadors de la zaqāt. Aquesta darrera apreciació mostra que els col-lectius beneficiaris de la zaqăt seran els mateixos musulmans que rebran els beneficis de ser musulmans. Es justifica així el pagament pel manteniment de la mateixa organització en què s'estan donant, on són principals executors els recaptadors d'impostos religiosos -els ulemes-, però també el califa i l'organització administrativa i militar que puga defensar els interessos consolidant-se $i$, per suposat, tot allo que puguen ser serveis per donar una mínima seguretat a l'estructura emergent: escoles i hospitals.

Resulta evident que a través de la zaqăt s'arriba a la consolidació i a l'expansió del grup; l'única condició per a rebre els beneficis $\mathrm{i}$ complir aquesta norma és la de pertànyer al col·lectiu, ser musulmà. Pero, que passa quan un musulmà es trobạ en una societat no islàmica?, o què passa quan un no musulmà es troba en una societat islàmica?. La racionalitat econòmica de l'islam discrimina per la religio, i això es transmet també als aspectes econòmics $\mathrm{i}$ fiscals. Així, aquell no 
musulmà que desenvolupa qualsevol activitat de tipus econòmic i que vol continuar sent no musulmà en aquelles terres conquerides per l'islam, ha de fer un pagament superior a l'Estat - té un impost superior - al de qualsevol musulmà per desenvolupar la mateixa activitat. Per contra, aquells musulmans que desenvolupen activitats fora de societats, estats $\mathbf{i}$ organitzacions islàmiques, no tenen per que fer front a impostos superiors als de la resta de persones per raó de la religió, per ser musulmans. Raons? La zaqät és la materialització de la consolidació de l'islam; per açò en una societat no islàmica, per a un musulmà no té sentit ètic el seu pagament perquè no cal consolidar i fer front a les necessitats de cap grup o organització. En canvi, en una societat islàmica, un que no siga musulmà i per a uns ulls musulmans, estaria aprofitant-se d'unes estructures que li permeten fer una activitat concreta, obtenir una determinada riquesa $i$, per tant, es justifica una compensacio; seria el pagament d'un dret d'assentament i d'explotació per aprofitar-se d'un sistema sòcio-econòmic determinat.

Cal remarcar que en l'islam són les estructures religioses les que consoliden, donen estabilitat $\mathrm{i}$ eixamplen la societat, a partir dels pagaments que es fa, siga per la zaqät, o siga pel pagament dels beneficis derivats de la guerra santa - l'expansió. L'Estat és quelcom afegit a posteriori, ja que a priori sempre serà la umma, la col-lectivitat derivada de la religiositat, la que dictamine sobre què fer, com fer-lo, etc, sobre la zaqãt. L'islam s'instal la sobre una societat religiosa, sense estat, i és precisament en la mesura que s'acompleixen les normes religioses, quan es permet que els estats es consoliden com a tals. Normes religioses que en aquest cas són de caràcter econòmic a través de la zaqãt, són les que donen suport monetari a la consolidació i a l'expansio de l'islam. La virtualitat material de consolidació, superació i creixement que l'islam arriba a tenir, es concreta en la zaqãt.

\section{La zaqāt: socialització de l'islam}

Recordem que els cinc pilars de l'islam són: professió de fe, oracio, dejuni, almoina i pelegrinatge. Tots cinc tenen una considerable transcendencia tan individualment com social. El sentiment de comunitat-col-lectiu islàmic que té cadascú dels musulmans, es deriva del 
convenciment que es té que la resta dels musulmans practiquen i comparteixen els mateixos principis, i es comporten d'una forma similar a la que ell pot tenir. Resulta evident que el compliment individual de les normes $\mathrm{i}$ dels principis islammics garanteix la persistència del col-lectiu de I'islam. No obstant aixd, la transcendencia tan individual com social és diferent atenent a cadascun d'aquests cinc pilars.

Tots cinc tenen un caràcter col-lectiu en la mesura que el seu compliment permet pertànyer a un grup. Tots cinc tenen un caràcter personalista $i$ individual per ser complits. Tots cinc tenen una relacio amb la vida quotidiana, fins al punt que per molt intimista que puga ser la celebració del ramadà, el pelegrinatge a la Meca, o la oració diària, tenen considerables conseqüencies exteriors, tant socials com economiques. Tanmateix, l'únic dels cinc principis islàmics que té una implicació social directa és l'almoina religiosa, la zaqãt, en la mesura que és l'unic de tots cinc que s'ocupa de la relació entre humans.

L'abast que arriba a tenir cadascun dels principis islàmics és eminentment religiós, derivat de la pràctica del creient. Però l'abast que arriba a assolir l'almoina religiosa és alhora religiós i social. Per això hem de considerar la zaqăt com el principi islàmic més socialitzant que hi ha en el si de la comunitat islàmica.

La característica socialitzadora que podem destacar en la zaqät no es desprén tan sols de posar de manifest una relació materialitzada entre humans. La relació socialitzant que inclou a més la zaqät, encara que responga a un dels actes piadosos de tot musulmà, es manifesta per ser un acte social que remarca la preocupació islamica per aspectes no piadosos i intimistes, i sí per aquells altres relacionats molt directament amb la situació material — siga de pobresa i marginalitat - d'una part de la societat que per raons diverses no arriba individualment a assolir cert nivell de benestar, o — siga de riquesa - d'una altra part del col-lectiu de musulmans que han arribat a assolir un cert nivell de renda i benestar.

Del compliment de fer l'almoina, se'n deriven quasi automàticament dues sensacions socialitzadores de gran transcendència: la seguretat i la universalitat. Així, en primer lloc, del compliment natural del precepte de fer l'almoina religiosa, se'n deriva una sensació de seguretat/protecció - fins i tot materialista- per pertànyer a un grup determinat; ja que en cas de necessitat, es pot cedir a través de 
l'almoina part de la riquesa d'aquells que tenen major benestar a aquells altres necessitats que es troben en una situació de pobresa. Del compliment natural del precepte de fer l'almoina religiosa, se'n deriva també la mateixa capacitat de créixer i enfortir-se, ja que en la mesura que s'acomplesca amb major rigor aquest precepte, hi haurà major quantitat de recursos per a posar-los a disposició de la col-lectivitat i fer front a les seues necessitats (Alcorà, 2: 254). La zaqät arriba a transmetre així una sensació a la comunitat islàmica de protecció, solidaritat i seguretat, alhora que de capacitat d'expansió i de possibilitat de creixement mentre s'estiga en el si de l'islam.

La fortalesa material de l'islam estaria així en la capacitat d'obtenció de recursos per part de la societat islàmica, la qual cosa es deriva directament del compliment del precepte religiós de fer la zaqät. La quantitat de recaptació pot variar en relació amb la base material sobre la qual s'aplica el recapte, de tal forma que com major siga la base -el nombre de musulmans i de béns i de riquesa d'aquests musulmans-, més gran serà la quantitat recaptada, la qual cosa possibilitarà així que hi puga expandir-se la presència de l'islam per la major capacitat que tindra, $i$, per tant, que tinga més riquesa.

De la mateixa manera, la socialització que es comprova a través del compliment de la zaqdit es deriva de la possibilitat que la zaqât transmet per assolir una sensació de comunitat per la universalització d'aquest precepte (Naqvi, 1981, 54; Herbert, 1987). En l'organització de qualsevol grup social, l'atenció que es pot tenir sobre aquell col-lectiu que posseeix béns, mitjans i propietats, té una transcendencia determinant. Generalment la importància de qualsevol grup rau en la importància que tinguen les seues propietats. Hi ha organitzacions socials que relacionen directament la capacitat social dels seus membres amb la seua capacitat econòmica. També hi ha societats excloents socialment pel fet que els seus membres no arriben a certs nivells de riquesa, propietats o benestar. Aquest, pero, no és el cas de l'islam, on precisament es pot veure que hi ha una diferenciació respecte als sistemes sòcio-econòmics de molt països de l'orbita occidental, perquè en l'islam la universalització dels preceptes obliga a comptar amb els desfavorits, que són una part més del sistema social que una organització sòcio-econòmica com la islàmica pot arribar a tenir. L'islam no admet l'exclusió de cap membre del grup per molt pobre que siga, com 
ho fan altres sistemes sòcio-econòmics; pot arribar a admetre $\mathrm{i}$ a propiciar les diferencies socials - l'explotació d'uns homes pels altresperò en cap moment permet l'exclusió, ja que sempre hi ha la possibilitat de vincular el desfavorit $i$ el menyscapacitat mitjançant l'almoina amb el sistema sòcio-econòmic vigent. És aixı́ que els menys afavorits se senten membres d'una comunitat que a través de la zaqät té obligacions morals i materials envers ells.

L'almoina religiosa és, doncs, l'element materialitzant i socialitzant de la mateixa religió. La zaqãt resulta ser un precepte religiós amb capacitats socialitzadores de gran transcendencia per a la comunitat islàmica. Mitjançant la zaqăt el musulmà se sent vinculat materialment i d'una forma concreta a la seua comunitat; serà membre d'aquesta comunitat en la mesura que acomplesca individualment amb el precepte, i serà exclos del grup tan sols quan deixe d'acceptar i de complir amb el precepte individual.

\section{La zaqāt: regulació econòmica de l'islam}

L'islam admet les diferències socials. Segons l'islam, aquestes diferències són conseqüència de diverses possibilitats: per les diverses consideracions que Déu ha tingut en afavorir més uns que altres, per raons de treball i d'esforç, per raons d'herència, etc. La riquesa, sempre que haja estat guanyada amb mitjans lícits (pel treball i de forma més destacada pel comerç), és la que permet assolir el màxim de benestar $\mathrm{i}$ fer front a les necessitats de la família; la riquesa obtinguda per un musulmà que acompleix les normes $\mathrm{i}$ els preceptes islàmics és una benedicció que Déu fa a l'home (Alcorà, 16: 97; 29: 7). No obstant aixo, en l'islam hi ha també una idea aparent que és possible assolir la justícia social, la igualtat i el benestar col-lectiu, mentre s'estiga en el si de la comunitat que respecta les normes islàmiques (Naqvi, 1981, 8596; Abbasi i alt., 1989; Ghaussy, 1990). Ser musulmà transmet un sentiment de confiança en el sistema islàmic, ja que quasi de forma automàtica hi ha la possibilitat d'assolir aquests objectius.

La primera regulació directa sobre la riquesa es troba de forma explícita en el mateix Alcorà i en la xarl'a, en la mesura que s'estan determinant límits i posant condicions als usos que es facen de la 
riquesa i de la propietat. Així es limita l'extravagancia en relació amb el consum (tot i que no està ben vista $i$ té consideració de menyspreu per aquell que ho faça), de la mateixa manera que s'esdevé amb el malbaratament; per altra banda, apareix l'obligació de compartir a través de la zaqăt -la imposició obligatòria-, i ja per fi, la regulació pel que fa a l'ús que es faça de la propietat està també sotmesa a les normes de l'herència.

Les regulacions anteriors, pero, posen de manifest que l'islam no prohibeix l'apropiació privada i tampoc posa un límit concret a aquesta apropiació. Per tant, serà l'islam, i no l'individu, el que arriba a assolir aquelles premisses de justŕcia social, igualtat $\mathrm{i}$ benestar econòmic $\mathrm{i}$ social. El mecanisme més adient per a aconseguir aquests objectius serà la zaqãt, l'impost religiós obligatori que tot musulmà ha de complir. Cal advertir que en l'islam hi ha tambe altres institucions i mecanismes que actuen en la mateixa direcció de protecció social i d'intentar assolir un benestar social, com ara la faḿlia o l'almoina voluntària (Etienne, 1992, 124; Messaoudi, 1990; Maaouia, 1991; Behnam i alt., 1986). No obstant això, aquestes institucions $\mathrm{i}$ instruments no tenen el nivell de normativitat que té la zaqdat.

Estrictament, la zaqãt és un pagament èticament obligatori de tipus religiós, piadós i moralitzant. Tanmateix, té també connotacions immediates de caràcter material, perquè és un mecanisme de regulació tant per a l'individu -el musulmà - com per al col-lectiu - l'islam. Per a l'individu, la zaqãt indueix a fer partícip a la col-lectivitat de la riquesa personal, i descarregar els més afavorits de la responsabilitat directa que tenen davant dels menys afavorits; crea així un cos únic entre els musulmans. La zaqăt serà, doncs, un mecanisme econòmic i moral de regulació automàtica que transmet un sentiment de solidaritat, justícia $i$ equitat - que no igualtat-, en què s'està participant d'un sistema socio-econòmic que permet l'equilibri en la mesura que possibilita un transvasament dels qui tenen més possibles cap a aquells més desfavorits.

La virtualitat de la zaqät, des de la vessant economicista, es manifesta com tot mecanisme impossitiu: discrimina en l'origen el subjecte $i$ la font d'activitat $i$ de riquesa que resulta gravada, i permet assignar directament el volum de recursos alliberats cap a una destinació determinada, amb la possibilitat d'induir efectes afegits positius per al 
consum, l'ocupació i l'activitat general de la col-lectivitat (Choudhury, 1986, 27 i ss. i 51-71; Pryor, 1985).

És diff́cil pensar que en l'origen de la instauració de la zaqăt es pretengueren assolir tots aquests objectius. Tanmateix, els efectes directes de la zaqãt són semblants als d'una política fiscal activa, i per tant cal assenyalar el fet de ser un instrument pioner de la política fiscal moderna no islàmica. A més a més, la zaqāt té una virtualitat digna de remarca enfront d'altres figures impositives modernes, com és el fet de ser un instrument d'autoregulació mentre que els impostos moderns estan sotmesos a una coacció externa sancionadora. Aço no vol dir que tan sols amb la zaqãt hi haja suficient disponibilitat financera com per a dur a terme una política d'equipament i d'incentivació de la demanda, havent de recórrer a altres tipus d'ingressos públics per fer front a les necessitats socials. La zaqãt està limitada financerament perque grava en percentatges no massa elevats en relació amb les necessitats públiques, però, a més a més, la possibilitat d'evasió és un altre component explicatiu del seu límit (Kuran, 1992a, 23-27; Diabi, 1993).

L'obligatorietat de fer la zaqăt és universal per a tot musulmà; es podrà fer efectiva en espècies; s'aplicarà segons la llei canònica -la sunna- sobre el $80 \%$ de la renda individual, així s'alliberen un $20 \%$ dels ingressos després d'haver restat exempta una quantitat mínima de renda. Tanmateix, i encara que la zaqät tracta de ser un impost proporcional fix respecte a la renda, i universal per a tothom, de fet, discrimina en funció de l'origen de la riquesa i de l'activitat que permet assolir-la. Així, tenint en compte si es tracta d'una renda agrícola o no agrícola, si es deriva de més o menys treball, si es tracta de renda provinent de béns productius o no, etc., la quantitat de zaqãt serà diferent tot $\mathrm{i}$ que la renda siga la mateixa ${ }^{5}$. És per aço que hi ha una

${ }^{4} \mathrm{Cal}$ recordar que en l'economia moderna, l'iniciador de la política fiscal activa fou Lord Keynes, que el 1936 publica el seu General Theory of Employment, Interest, and Money, on planteja la necessitat d'incentivar la demanda agregada a partir, entre altres coses, de dur a terme una política fiscal. Per a una aplicació del model keynesià sobre la base dels principis econòmics islàmics, vegeu Choudhury, 1986, ps. 172-186, on utilitza la zaqăt com un impost directe sobre la inversió, no superior al $2,5 \%$ dels beneficis.

${ }^{5}$ Alguns dels problemes que tipus pràctic que es poden veure en l'aplicació 
possible arbitrarietat en aplicar un percentatge o altre a una quantitat de renda. D'altra banda, l'arbitrarietat pot ser intencionada i de la qual la zaqät participa encara que no és exclusiva de la zaqät (Kuran, 1992b). Amb l'objectiu d'unificar criteris sobre el percentatge de zaqăt que cal aplicar, s'arriba a establir un 2,5\% sobre els rendiments economics en general, encara que caben prou matisacions (vegeu Mannan, 1986, 243281).

Encara que siga necessari remarcar la possible arbitrarietat individual que pot arrossegar la zaqāt com a pagament efectiu, el que resulta més transcendent no és la quantitat desembossada o transferida, sinó la implicació qualitativa que arriba a tenir l'aplicació de la zaqăt (Esposito, 1987). De fet, des d'un punt de vista social el que importa de la zaqăt és el mecanisme que exerceix com a instrument regulador de l'activitat economica i social, i que permet alhora que s'inicie un brot d'estat del benestar (Choudhury, 1986. 111-113). Una de les accions més clares a partir dels fons de la zaqät ha estat el finançament, encara que la majoria de les vegades amb manca de diners, fet que dóna com a resultat no massa bons serveis de prestacions educatives, sanitàries, protecció social, treball i béns públics (Mannan, 1986, 266; Nienhaus, 1990; Monde Arabe. Maghreb-Machrek (dossiers et documents) 1992; Ben Nefissa, 1993).

\section{La zaqät: immobilisme I classisme a l'islam}

El fet que cap musulmà estiga exclòs del grup social que representa l'islam, no permet traure com a conclusió que l'islam és un sistema sòcio-econòmic participatiu; més aviat al contrari. La justicia distributi-

concreta de la zaqāt, és que la base imposable sobre la qual s'aplica el percentatge de gravamen està prefixant la rendibilitat de l'activitat determinada; així, si la terra és regada o no, els percentatges en què s'aplicarà la zaqat són diferents (entre el 5 i $10 \%$ dels guanys), la qual cosa no respon a una veritable determinació de la renda agrària. El significat de renda pot ser diferent al de benefici o de guany, ja que caldrà saber si se'n descompten o no les despeses de producció. La zaqăt s'aplica directament sobre la possessió de béns productius al marge que estiguen o no en el procés de producció. 
va, la protecció dels desfavorits i l'equilibri social, es plantegen com a objectius assolits mentre s'estiga en el si del mateix islam; per al musulmà automàticament es donaran aquests objectius en funció de la seua pertinença a l'islam. D'aquesta manera, l'individu pot ser conservador perque l'islam ja és revolucionari; l'individu pot ser moderat perquè l'islam és extremat. Amb aquesta doble perspectiva es pot caracteritzar l'islam: d'una banda, la moderació en el marc de l'individu i de la persona; en canvi, el sistema comporta un fort missatge de canvi i de revolució. Per açò en l'islam hi ha la realitat de l'immobilisme i del conformisme individual (Amin, 1988, 333-357; Scarcia, 1982), alhora que s'hi dóna la potencialitat del canvi i de la revolució que apareix de forma automàtica pel fet de pertànyer al grup. És l'islam el que garanteix la igualtat i la justícia distributiva, segons l'opinió que "els pobres tenen dret a part de la riquesa dels rics". El problema és saber com es produeix açò i quines conseqüencies se'n deriven (Bazzichi, 1988; Behdad, 1989; Behdad, 1992, 92-96).

Aquest immobilisme $i$ aquesta manca de participació activa en la vida i en l'esdevenir del grup que caracteritza el musulmà, es pot justificar concretament des de l'islam mitjançant la zaqãt (Etienne, 1992, 133) i la condemna moral que es fa en la mesura que puga existir un repartiment desigual de la riquesa. D'aquesta forma, l'acumulació $\mathrm{i}$ l'explotació no són termes aliens a l'islam (Palloix, 1980; Haque, 1992; Rodinson, 1972; Rodinson, 1993, 177-213), pero no tenen resposta des d'una perspectiva personal $\mathrm{i}$ individual, ja que és l'islam el que té l'obligació de reparar els possibles desavantatges generats en el sistema per una excessiva acumulació de riquesa.

Fins i tot, els possibles efectes derivats d'una política redistributiva a partir de la zaqãt, per al musulmà no són tan evidents. La valoració ètica i moral que el musulmà té de la zaqăt en relació amb la justícia distributiva $i$ amb l'equilibri social que transmet, es concreta en una cessió temporal de la propietat de l'individu cap a la col-lectivitat, de tal forma que en cas de necessitat, aquesta cessió serà transferida novament al seu origen - a l'individu - per part de la societat. Per a l'individu, la zaqãt apareix com a una espècie de dipòsit temporal dels seus béns materials en una societat que, si ho necessita en un futur, pot tenir l'oportunitat de reprendre'ls. Seria aixi com una possibilitat d'estalvi (diposit diferit), mentre hi haja altres correligionaris que 
acomplesquen amb el precepte de fer la zaqãt de la mateixa forma que el subjecte ho està fent en aquest moment.

D'aquesta forma, la imposició religiosa obligatòria - la zaqãt- no és un acte revolucionari a partir del qual es desenvolupa una acció redistributiva entorn de la riquesa. Més aviat al contrari, ja que mitjançant la zaqãt es planteja una política reformista (Puel, 1990, 1719) i preservativa de la mateixa riquesa. Des d'un punt de vista maximalista es podria parlar en l'islam de respecte al principi de coparticipació, però sempre respectant el fet que és l'individu-propietari qui cedeix temporalment a la societat els seus béns. Finalitzem, doncs, amb la convicció que l'islam desincentiva l'acció reivindicativa de l'individu i manté un status quo en relació amb l'ordenació social i la logica d'explotació d'una societat classista.

\section{Referències bibliogràfiques}

Abbasi, S.M.; K.W. Hollman; J.H. Murrey (1989), "Islamic Economics: Foundations and Practices", International Journal of Social Economics, vol, 16, 5: 5-17.

Amin, S. (1988), La desconexión: hacia un sistema mundial policéntrico, Madrid: IEPALA.

Bazzichi, O. (1988), "Sistema economico islamico e sua possibilità di coesistenza con i princípi dell'economia di mercato", Rivista di Politica Economica, vol. 78, 5: 617-627.

Behdad, S. (1989), "Property rigths in contemporary islamic economic thought: a critical perspective", Review of Social Economy, 2: $185-211$.

Behdad, S. (1992), "Property rigths and Islamic Economic Approaches", in Jomo K.S. (edit), Islamic Economic Alternative. Critical Perspectives and New Directions, London: MacMillan, ps. 77104.

Behnam, D.; S. Bouraoui (coords.) (1986), Familles musulmanes et modernité. Le défi des traditions, Paris: Publisud.

Ben Nefissa, S. (1993), "Le financement des services sociaux du secteur associatif à référent islamique", Egypte, monde arabe, 12-13: 213 i ss. 
Choudhury, M.A. (1986), Contribution to Islamic Economy Theory: A Study in Social Economics, New York: St. Martin's Press.

Diabi, A. (1993), "The concept of Zakah evasion: an economic interpretation", Review of lslamic Economic, vol. 2, n. 2: 17-28.

Esposito, J.L. (ed.) (1987), Islam in Asia: Religion, Politics, \& Society, New York: Oxford University Press.

Étienne, B. (1987), L'islamisme radical, Paris: Hachette.

Étienne, B. (1992), "La culture islamique est-elle compatible avec l'economique moderne", in AA. DD. Régions et Pays Mediterranéens au début des années 90, tome 1, Les Milles: Centre d'Economie et de Finances Internationales, ps. 119-140.

Ghaussy, G. (1990), "Étude sur la théorie de l'ordre économique islamique" in G. Beaugé (coord.), Les capitaux de l'Islam, Paris: CNRS, ps. 35-49.

Haque, Z. (1992), "Islamic Perspectives ans Class Interests", in Jomo K.S. (edit.), Islamic Economic Alternative. Critical Perspectives and New Directions, London: MacMillan, ps. 105-116.

Hasanuz Zaman, S.M. (1991), Economic Functions of an Islamic State, Karachi, Leicester: The Islamic Foundation.

Herbert, J.L. (1987), "Economie Islamique ou Politique Economique Musulmane?", Revue Mountaka, 18: 61-73.

Kuran, T. (1992a), "The Economic System in Contemporany Islamic Thought", in Jomo K.S. (edit.), Islamic Economic Alternative. Critical Perspectives and New Directions, London: MacMillan, ps. 948 .

Kuran, T. (1992b), "Economic Justice in Contemporany Islamic Thought", in Jomo K.S. (edit.), Islamic Economic Alternative. Critical Perspectives and New Directions, London: MacMillan, ps. 49-76.

Maaouia, A. (1991), "Vécu et representation du chomage. Enquête realisée auprès d'un groupe de jeunes gens à Tunis", Revue Tunisienne de Sciences Sociales, 101: 83-122.

Mannan, M.A. (1986), Islamic Economics: Theory and Practice (Foundations of Islamic Economics), revised edition, Sevenoaks, Kent, U.K.: Hodder and Stoughton.

Messaoudi, A. (1990), "Chomage et solidarités familiales", Peuples méditerranéens, (esp. "Algérie. Vers l'état islamique?"), 52-53: 195218. 
Monde Arabe. Maghreb-Machrek (dossiers et documents) (1992), "Systèmes de santé et systèmes de protection sociale dans le monde arabe", Monde Arabe. Maghreb-Machrek, 138: 111-125.

Naqvi, S.N.H. (1981), Ethics and Economics: An Islamic Synthesis, Leicester, U.K.: Islamic Foundation.

Nienhauș, V. (1990), "Les biens publics et la politique financière dans une économie islamique" in G. Beaugé (coord.), Les capitaux de l'Islam, Paris: CNRS, ps. 123-134.

Palloix, Ch. (1980), "Un essai sur la formation de la classe ouvrière algérienne", Tiers Monde, 83: 557-574,

Pryor, F.L. (1985), "The Islamic Economic System", Journal of Comparative Economics, 9; 197-223.

Puel, H. (1990), "Les droits économiques et sociaux en Islam. Un point de vue chrétien", Islamochristiana, 16, 15-23.

Rodinson, M. (1972), Marxisme et monde musulman, Paris: Editions du Seuil.

Rodinson, M. (1993), L'islam politique et croyance, Paris: Fayard.

Scarcia Amoretti, B. (1982), "Pour une analyse politique de l'économie islamique", La Pensée, 229: 62-70. 